\title{
Approaches to Promote Educational and Research Activities among the Students of Faculty of Philology in the Course of their Teaching Training
}

\author{
Lyudmila A. KAREVA \\ Ph.D. (Pedagogics), Associate Professor \\ Associate Professor of the Foreign Philology Department \\ Faculty of Philology \\ North-Eastern State University \\ 13 Portovaya Str., Magadan, 685000, Russia \\ kafinyaz@svgu.ru \\ Sofia D. BAYUKOVA \\ 4-year Student \\ Foreign Philology Department \\ Faculty of Philology \\ North-Eastern State University \\ 13 Portovaya Str., Magadan, 685000, Russia \\ Sofia_Bayukova@mail.ru
}

\begin{abstract}
The article discusses the co-relations between educational, academic and scientific research activities of students over their on-the-job and teaching training spans. The authors believe that one of the ways to integrate education, job execution and science may be the performance of a group of students supervised in accordance with the principle of an academic research group carrying out a scope of academic and research cross-curriculum assignments of the cognitive theoretical and experimental type. Proposed are the strategies for cognitive research team activities as regards the introduction of integrative academic and scientific research tasks during the teaching training of students. The purpose of this study is to expand the academic and research activities of students in the course of their school teaching training. The authors suggest a set of academic and research cross-curriculum assignments to enhance the teaching and educational process at school. The students creative output allows to effectively implement curricular activities, and introduce integrative academic and research assignments into teaching and extracurricular activities.
\end{abstract}

Keywords: academic and scientific research activities; professional learning and research activities; teaching training; strategies; dynamic control system.

\section{Introduction}

In the core areas of higher and secondary vocational education, the attention of the university teaching staff is focused on the necessity to ensure integration of education, job execution and science in the process of professional training, and that implies a tight co-relation between educational, academic and scientific research activities of students all the way through their on-thejob and teaching training spans. Taking into account the fact that nowadays the entire scientific research teams as the integral systems represent the knower in the society and not just the mere conglomerates of individual researchers, in the process of their university education the students should master the techniques not only individually, but also as part of the collective research activity. Meanwhile, traditionally in the academic environment when studying the subjects of philological, social and political, psychological and pedagogical curricula, and as well as when doing the on-the-job and teaching training, the individual academic and research student activities dominate. This offers a solution to only one of the mentioned above problems. Therefore, an active 
search is currently underway to discover methods to improve the professional skills of students by involving them into various types of team work (Polyakova, 1983, pp. 100-101) which bears social and professional significance.

One of the ways to integrate education, job execution and science may be the performance of a group of students in the course of teaching training at school supervised in accordance with the principle of an academic research group, with all the participants performing a particular scope of academic and research cross-curriculum assignments of the cognitive theoretical and experimental type, and collectively studying one of the topical problems in view of the optimization of the teaching and educational process at school. Among such subject matters for students of the language department can be the following: Integrated approach to conducting country-oriented extracurricular activities in a foreign language in final school years; Structure and content of career guidance of a teacher of foreign languages at various educational stages at school; Exercises in communication as means of teaching the norms of foreign language communication in school years of 5 to 7; Formation of the political culture awareness in students of final school years through foreign languages, etc. (Collie, Shapka, Perry, 2012).

At that, particular attention should be paid to fashioning the strategies and principles of professional cognitive and research activities in the to-be-teachers when solving various scientific, methodological and educational problems, improving the ethics of scientific and professional communication, developing the social and professional reasoning and scientific and pedagogical speech culture (Aretanov, Pidkasisty, Khaidarov, 1980). In other words, for students their on-thejob teaching training being a distinct example of the human activity serves as follows:

the driver of students' knowledge in the field of topical problems in psychology, pedagogics and methods of teaching foreign languages at school by way of summarizing theoretical achievements and advanced pedagogical best practice, psychological, didactic and methodological analysis, style and content of pedagogical activities of the practicing teachers;

the incentive for further development of social, pedagogical and methodological reasoning by way of finding the optimal solutions to educational, practical, scientific and methodological problems;

the means of secondary socialization of the trainees provided that their educational, pedagogical and research activities ensure the becoming of a skilled expert in the unity of individual, collective and social interests;

the means of developing pedagogical skills of the to-be-teachers of foreign languages by way of professional communication with the school teaching staff, advanced teachers of foreign languages, the faculty and/or ministry, and high school teaching staff.

Three main stages are distinguished in the academic and research pedagogical activity of the students during their teaching training:

elaboration of the plan and program for cognitive and research activities of the group as a whole, and each of its members individually;

implementation of the collective cognitive and research activities program for the students, and control over the quality of work and its outcome;

critical analysis of the outcome of the activities of the group members, and generalization of the outcome of the scope of integrative interdisciplinary tasks during verbal or written communication in native and foreign languages (Kareva, 2019).

\section{Methods}


The first stage of students' research and development activities under the supervision of a methodologist involves introduction of the teachers-to-be to the planned cognitive research subject matter and fashioning among them the associated concepts of the collective cognitive research activity strategy when working on it, as well as getting the students familiar with the functions of a student group methodologist and a coordinator in view of ensuring control over the quality of the work of the group as a whole, and each of its members individually. In addition, the students of the academic and research group design the scope and its timing for the intended set of academic and research tasks by the group as a whole, and each of its members individually (Akhmetshin, Vasilev, Ustyuzhina, 2016; Elmendorf, Song, 2015)

Introduction of the students into a cognitive research topic involves, primarily, the induction of the teachers-to-be through the extent of its scientific development based on the analysis of achievements in the national and world science in relevant fields of knowledge. In particular, introduction into the cognitive research on Formation of the political culture awareness in students of the final school years through foreign languages provides for getting the students familiar with the achievements of a) social sciences in studying the problem of political culture formation among the youth; b) pedagogics in developing the problem of formation of patriotic education in schoolchildren in the unity of educational and extracurricular, cognitive, social and political activities and work life; c) psychology and didactics in developing the general theoretical foundations of discovery teaching; d) methods in developing the problem of enhancing communicative and cognitive activities in students in the context of communication in a foreign language, as well as the problem of implementation of patriotic education for schoolchildren through foreign languages. In the second place, introduction into the cognitive research area is based on the critical problematic understanding of the practicing teachers experience through the prism of the present-day requirements for the foreign language lesson at different school stages and for the related didactic and methodological factors affecting implementation thereof in the educational process. Thirdly, it presupposes the discussion on the importance of practical educational and methodological work of students in testing the achievements of the national and world best practice in the field of foreign language lessons, elective courses and during extracurricular activities (Curry, Webb, Latham, 2016).

While tailoring the strategy of collective cognitive research among the teachers-to-be, the set of questions for the group discussion with a methodologist includes as follows:

determination of scientific and educational methodological aims and objectives in view of implementation of the planned cognitive research problems and responsibilities of every group member in the course of solution thereof;

formulation of a working assumption, and discussion of possible ways to develop it;

preliminary mental visualization of the forthcoming theoretical and empirical outcome of the cognitive and research activities being discussed by the group;

analysis of the specifics of the study objective and determination of the possibilities to use such research methods as pedagogical observation, pedagogical experiment, sociological method, theoretical analysis and synthesis of pedagogical phenomena;

elaboration of plans and stages of the cognitive research activities and contents thereof for the group as a whole followed by substantiation of the educational research set of tasks for every teaching trainee.

Once the aims of the cognitive research activities of the group of students correlate with the methods and conditions for their achievement, the students proceed with planning the scope and timing for the envisioned types of work in part of processing literary sources, methodological and 
didactic analysis of the best practice of teachers and peer observation focusing on the their research topic, generalization of scientific achievements in the field of the national and world pedagogics, psychology and methods of teaching foreign languages. That also implies conducting experimental work on the introduction of advanced methodological practices into the educational process, developing a series of foreign language lessons and extracurricular activities that represent the practical implementation of the results of the work on the cognitive research topic (Borisov, 1986; Puzhurin, Pizhurin (Jn.), Pyatkov, 2015). When planning the scope and timing to implement the academic and research activities, the extent and ratio of theoretical cognitive and approbatory testing activities of the students are determined, the time is allocated as per the phases of implementation of the designated amount of work and determination of the terms and forms of collective and individual reporting to the group senior and the university methodologist. The competence of students in view of the approach to perform research activities in the field of pedagogics is also summarized.

The second stage of the academic and research activities of the group of students is characterized as follows: a) the extent of competence (previously mastered in view of specific and social subjects) required and sufficient for the high-quality implementation of individual cognitive research tasks and the entire complex thereof, and the possibility of their proactive application in the research conducted by students; b) the significance of each of the planned cognitive research problems solved by the group members in the overall structure of the team work is specified; c) the possible boundaries of succession are established in terms of application of the research methods and techniques and the use of the results of some cognitive research problems to solve the others; d) storing and recording of the experience of the team implementation of the research activities in such report forms as Express Information; e) the quality and scope of the research work performed is assessed, and the decision is made on its practical significance for the foreign language teaching practice at school. Interaction of the academic, pedagogical and cognitive research activities of students before their training starts is carried out by way of combining the team effort of the academic research group as regards the methodological, psychological and comprehensive analysis of the foreign language open lessons with topical workshops on various aspects of the studied cognitive methodological areas and the difficulties arising in the course of their elaboration.

In the course of critical discussion of the results of cognitive-research activities carried out by the group, and generalization of the results of the set of integrative cross-curriculum activities done by the group members under the guidance of a methodologist, the theoretical and empirical reliability of the results obtained by the students in the course of their academic and research tasks is analyzed and compared with the data of this kind of research available in the national and foreign practice. The sufficiency of the educational research strategy and tactics of the cognitive activity of students is determined in accordance with the purpose of the study and its objectives, with particular attention paid to the issues of the scientific work culture and rational approach to its implementation, as well as the issues of professional communication efficiency with the teachers of foreign languages and student group coordinators. Ethical issues of the professional and scientific communication of every group member in on-the-job and professional situations and their impact on the efficiency of collective educational research activities are subject to the detailed discussion.

\section{Results}

The results of cognitive research activities carried out by the students are presented as a team project covering the most relevant aspects of the subject matter, providing practical and methodological recommendations for school teachers and on teaching materials based on the outcome of the cognitive experimental study of the subject matter and psychological and methodological aspects of teaching foreign languages at any particular stage of school education (Golubeva, Babaeva, 1980). 
The results of the group study are summarized by means of the team report and presentation. The structure and content of the team project is discussed in advance. The general requirements to the writing procedure are assembled, and the scope of work is distributed among the group members. Such a report is used further by the group members when preparing for the round table at the final conference on teaching training, at practical workshops when the students present at workshops and seminars and during their participation at tutorials in student methodology, at career guidance sessions of the final year students with the students of the $1-2$ years.

As the training experience proves, introduction of the team integrative academic and research activities in the course of teaching training of students can effectively contribute to improving the students cognitive and research skills, professional communication aptitudes in the exercise of educational, methodological and research activities, as well as scientific and organizational competences in planning, conducting and monitoring team research. However, highlighting the educational and methodological feasibility of the form of work as described above, it should not be considered as absolute since its efficiency depends largely on the level of the psychological and professional readiness in students to solve creative tasks of the cross-curriculum nature. That can be formed when using a holistic approach to the educational process management, development of general intellectual and special skills, including, in addition to the integrative research crosscurriculum tasks suitable for team work in the course of teaching training, such components as professionally directed philological, literary and psychological methodological research tasks of different complexity (Safonov, 1986); cross-curriculum and domain-specific discussions (Shmidt, Stock, 1984, pp. 23-25); and professional simulation games (Bayukova, Kareva 2019) when the fundamental subjects and communication and socially oriented foreign-language tasks are studied when completing practical courses of the first and second foreign languages. At that, the degree of intellectual competence of the structure and content of the mentioned above active forms of university training of the future specialists is based on dynamics of the professional competence development, on the culture of mental work and speech (in both native and foreign languages), and on the culture of professional communication at any particular stage of vocational training at the university. Besides, the requirements to the graduates indicated in the qualification profile, as well as the job specification of the future graduates of any particular department and university are accounted for. It should be considered, that the hierarchical sequence of introduction of various types of academic creative tasks to the students of different training stages at the university, in turn, is determined by the purpose of each and every of them. This implies the development of professional thinking, professional competences, the culture of mental work, speech and communication, the range of methodological acceptability as regards the type of university training stage and its type, the psychological and cognitive characteristics of students, didactic and methodological specifics of the studied disciplines and types of the empirical academic activities at the university.

\section{Discussion}

Introduction of the dynamic system to manage the formation of creative potential in to-bespecialists during the university years requires certain restructuring as regards the principles of the university education. It focuses, primarily, on the integrated approach to the formation of a highly qualified skilled expert and their personality in the contemporary society. Secondly, it is required to ensure a motivational basis for training a to-be-specialist in a particular type of higher education institution, and provide professionally oriented training for the students through educational process by way of the cross-curriculum integration of educational and methodological activities of different faculties. Thirdly, it is required to implement an active approach to formation of the dialectic thinking, imagination, cognitive activity and independence in students, as well as such core personality traits as initiative, creativity and civic consciousness. Fourthly, it is required to ensure a harmonious science-based combination of the individual and team forms of work in view of the 
academic and research activities for the university students. We believe that the qualities of the teachers conscious of self-development and self-actualization, should include as follows: selfacceptance (assertion of responsibility to themselves); harmony and inner accord of their selfidentity; abilities to reflect, evaluate and control their emotions, choose a type of behavior and selfcontrol; knowledge of themselves, of their psychophysiological characteristics, such as reactions, functions, aspirations, abilities, disposition, and, consequently, their character features, style and standpoints of their own life; recognition and acceptance of the environment, existence of others, external image of the world; positive outlook (confidence that the world around is viable, harmonious, humane); ability to understand, express empathy and compassion for others; selfesteem and the sense of self-worth (high self-appraisal regardless of individual personal achievements and gains); alertness and the search for new types of relationships with others; focus on overcoming professional issues, optimism, stress resistance; desire to achieve the set goals; recognition and readiness for the constant search for goals, ideals, higher suprapersonal values and meanings of life; emotional and intellectual independence, readiness to make a self-sufficient professional choice; involvement into the present; ability to enjoy the chosen professional path, to rejoice and be happy. Thus, the listed qualities of the teacher's personality should be in picture when evaluating the results of their activities.

\section{Conclusion}

The research data presented in the paper are intended for the use of students specializing in the fields of pedagogics, methodologists, training supervisors, teachers, and educational staff. The objective of the article is to ameliorate professional competences, abilities and skills of the to-beteachers in the course of training with reliance on the achievements in academic and research activities of the philological department students. By improving the academic approach at the department of philology in higher education institutions focusing on the areas as described in the paper creates substantial prerequisites to ensure training of highly qualified teaching staff capable of teaching and developing schoolchildren in accordance with the requirements imposed by the world of today.

\section{References}

Akhmetshin, E.M., Vasilev, V.L., Ustyuzhina, O.N. (2016). The development of education clusters as a tool to enhance economic safety. The European Proceedings of Social and Behavioural Sciences (EpSBS), XII, 411-416. http://dx.doi.org/10.15405/epsbs.2016.07.65

Aretanov, M.D., Pidkasisty, P.I., Khaidarov, Gh.S. (1980). Problematic and modelled education. Almaty: MEK.TEP. 9-13. (in Russian)

Bayukova, S.D., Kareva L.A. (2019). Difficulties in learning vocabulary and ways to overcome them. L International scientific readings (Tribute to A.M. Butlerov), 19-23.

Borisov, V.S. (1986). Educational and research work of students in teaching foreign languages during the final years at the linguistic university. Foreign languages at school, (1), 58-61. (in Russian)

Collie, R.J., Shapka, J.D., Perry, N.E. (2012). School climate and social-emotional learning: Predicting teacher stress, job satisfaction, and teaching efficacy. Journal of Educational Psychology, 104(4), 1189-1204. https://doi.org/10.1037/a0029356

Curry, J.R., Webb, A.W., Latham, S.J. (2016). A content analysis of images of novice teacher induction: First-semester themes. Journal of Educational Research and Practice, 6(1), 4365 . 
Elmendorf, D.C., Song, L. (2015). Developing indicators for a classroom observation tool on pedagogy and technology integration: a Delphi study. Computers in the Schools, 32(1), 119. https://doi.org/10.1080/07380569.2014.967620

Golubeva, L.R., Babaeva, T.P. (1980). Term papers in pedagogics and their role in formation of scientific and methodological skills in to-be-teachers. Problems of improving the system of psychological and pedagogical training of teachers. - Leningrad [St. Petersburg], 1980. 153165. (in Russian)

Kareva, L.A. (2019). Reliance and consideration of the mother tongue in the process of foreign language instruction. Modern Scientist, (1), 68-72. (in Russian)

Polyakova, T.S. (1983). Analysis of difficulties in teaching activities of novice teachers. Moscow: Pedagogy. 100-101. (in Russian)

Puzhurin, A.A., Pizhurin (Jn.), A.A., Pyatkov, V.E. (2015). Methods and means of scientific research: Textbook. Moscow: INFRA-M. (in Russian)

Safonov, V.V. (1986). On introduction of elements of problem-based learning at university language departments. Ways to implement the problem-based approach to teaching foreign languages, 56-64. (in Russian)

Shmidt, W. Stock, E. (1984). Rede - Gesprach - Diskussion. Leipzig: VEB Bibliograpliiches Institut, 23-25. (in German) 